\title{
Modulatory Function of Invariant Natural Killer T Cells in Systemic Lupus Erythematosus
}

\author{
Yi-Ping Chuang, ${ }^{1}$ Chih-Hung Wang, ${ }^{2}$ Ning-Chi Wang, ${ }^{3}$ \\ Deh-Ming Chang, ${ }^{4}$ and Huey-Kang Sytwu ${ }^{1}$ \\ ${ }^{1}$ Department of Microbiology and Immunology, National Defense Medical Center, Taipei 114, Taiwan \\ ${ }^{2}$ Department of Otolaryngology-Head \& Neck Surgery, Tri-Service General Hospital, National Defense Medical Center, \\ Taipei 114, Taiwan \\ ${ }^{3}$ Division of Infectious Diseases and Tropical Medicine, Department of Internal Medicine, Tri-Service General Hospital, \\ Taipei 114, Taiwan \\ ${ }^{4}$ Department of Internal Medicine, Tri-Service General Hospital, Taipei 114, Taiwan
}

Correspondence should be addressed to Huey-Kang Sytwu, sytwu@ndmctsgh.edu.tw

Received 2 January 2012; Accepted 10 April 2012

Academic Editor: Harris Perlman

Copyright (c) 2012 Yi-Ping Chuang et al. This is an open access article distributed under the Creative Commons Attribution License, which permits unrestricted use, distribution, and reproduction in any medium, provided the original work is properly cited.

\begin{abstract}
Systemic lupus erythematosus (SLE) is a chronic autoimmune inflammatory disease with complex immunological and clinical manifestations. Multiple organ failure in SLE can be caused by immune dysfunction and deposition of autoantibodies. Studies of SLE-susceptible loci and the cellular and humoral immune responses reveal variable aberrations associated with this systemic disease. Invariant natural killer T (iNKT) cells are a unique subset of lymphocytes that control peripheral tolerance. Mounting evidence showing reductions in the proportion and activity of iNKT cells in SLE patients suggests the suppressive role of iNKT cells. Studies using murine lupus models demonstrate that iNKT cells participate in SLE progression by sensing apoptotic cells, regulating immunoglobulin production, and altering the cytokine profile upon activation. However, the dichotomy of iNKT cell actions in murine models implies complicated interactions within the body's milieu. Therefore, application of potential therapy for SLE using glycolipids to regulate iNKT cells should be undertaken cautiously.
\end{abstract}

\section{Introduction}

Systemic lupus erythematosus (SLE) is a chronic autoimmune inflammatory disease with complex immunological and clinical manifestations. Reduced immune tolerance and abnormal activation of $\mathrm{T}$ and $\mathrm{B}$ cells lead to autoantibody production mainly against protein-nucleic acid complexes, such as chromatin, and small ribonucleoprotein particles. These autoantibodies complexed with their cognate selfantigens deposit within capillaries of various organs and subsequently mediate systemic disorders. The commonly affected organs include the skin, heart, kidneys, lungs, joints, and central nervous system. This disease usually begins in the 20-45-year age range, although it can occur at nearly any age. SLE is more common in women than in men $(>8: 1)$. Studies using animal models suggest a role of estrogens in the disease development. The induction of SLE depends on hereditary factors and environmental agents, and inherited genes, infections, ultraviolet light, and some medications are all involved. In general, triggers causing cell death, inefficient clearance of apoptotic cells, and improper exposure of intranuclear antigens to an uncontrolled immune system are potential causes of SLE [1].

Reduced immune tolerance leading to an overt immune response normally precludes various autoimmune disorders. Regulatory T-cells play important roles in mediating peripheral tolerance and immune cell homeostasis. Among them, the natural killer T (NKT) cells are a unique subset of T lymphocytes. NKT cells, which express both NK1.1 and the $\mathrm{T}$ cell receptor (TCR) in humans and most murine models, are heterogenous containing both CD1d-restricted and CD1d-nonrestricted populations. CD1d-restricted NKT 
cells might recognize glycolipids presented by CD1d for development and activation. Type I NKT cells within the CD1d-restricted population express an invariant TCR in the mouse $(\mathrm{V} \alpha 14 \mathrm{~J} \alpha 18)$ and human $(\mathrm{V} \alpha 24 \mathrm{~J} \alpha 18)$ combined with a limited but not invariant TCR $\beta$ chain repertoire (preferentially $\mathrm{V} \beta 8.2, \mathrm{~V} \beta 7$, or $\mathrm{V} \beta 2$ in the mouse and $\mathrm{V} \beta 11$ in human) [2]. These cells are thus classified as invariant NKT (iNKT) cells that account for more than $80 \%$ of CD1d restricted NKT cells in mice. Type II NKT cells are also CD1drestricted; however, they express variable $\operatorname{TCR} \alpha \beta$ chain combination and are difficult to identify. The most potent agonist of CD1d-restricted NKT cells, $\alpha$-galactosylceramide ( $\alpha$-GalCer), a synthetic glycolipid similar to that from an extract of marine sponges, is used widely to define the number and function of type I NKT cells [3]. In this paper, we use the term "iNKT cells" to describe CD1d-restricted NKT cells; however, methods used to identify these cells are described in the text when relevant to avoid confusion.

iNKT cells are innate-like lymphocytes. Immediately upon activation through TCR engagement, iNKT cells secrete a wide array of cytokines and chemokines. These cells also exert cytolytic activity through granzyme B and FasL-induced apoptosis. iNKT cells can upregulate CD80, CD86, and CD40 on antigen-presenting cells (APCs) to mediate downstream immune responses. Therefore, iNKT cells are considered effector cells that bridge the innate and adaptive immune response [4]. iNKT cells are associated with various autoimmune diseases, including type I diabetes experimental autoimmune encephalomyelitis, and arthritis [5]. Studies also indicate that the number and function of circulating iNKT cells decrease in SLE patients although the immunophysiological role of iNKT cells in SLE is unclear.

Various murine lupus models have been used to investigate the effects of the aberrant number and function of iNKT cells on disease activity. MRL/lpr mice, which have a defective point mutation in Fas, spontaneously develop inflammatory lesions affecting the skin and kidneys with marked lymphoproliferation and autoantibody production. CD1d-deficient MRL/lpr mice show exacerbated skin lesions [6]. The other widely used murine model, NZB/W F1 (BWF1) mice show an increase in activated iNKT cells with age; however, CD1d deficiency accelerates the onset and progression of nephritis [7]. A chemical-induced lupus model showed that exposure to hydrocarbon oils, such as pristane, facilitates SLE progression through an unknown mechanism. CD1d deficiency exacerbated lupus nephritis in this model, suggesting a regulatory role of iNKT cells [8].

In this paper, we discuss recent studies using different murine models to identify the possible roles of iNKT cells in SLE.

\section{Numerical Deficiency of iNKT Cells in Human SLE}

Changes in the number of iNKT cells are associated with many autoimmune disorders in humans, such as SLE, psoriasis, rheumatoid arthritis, and myasthenia gravis. In human SLE, iNKT cell number is measured using various methods.
Measurement of the expression of TCR V $\alpha 24 \mathrm{~J} \alpha 18 \mathrm{mRNA}$ level indicates that the numbers of invariant TCR V $\alpha 24 \mathrm{~J} \alpha 18^{+}$ CD4 CD8 double negative (DN) $\mathrm{T}$ cells are reduced in peripheral blood lymphocytes and in the rheumatoid synovium of patients with SLE [9, 10]. Flow cytometry shows that the number of DN NKT cells expressing TCR $\mathrm{V} \alpha 24 / \mathrm{V} \beta 11$ is lower in the blood of SLE patients than in healthy controls [11]. Because SLE patients develop progressive lymphopenia, the absolute cell number is affected by the reduction in total lymphocyte number. The proportion of iNKT cells can be calculated to determine the level. The frequency of NKT cells (percentages of $\mathrm{CD}^{2} 6^{+} \mathrm{CD} 3^{+}$ $\mathrm{T}$ cells among all lymphocytes) is lower in patients with SLE than in controls [12]. Studies using 6B11 monoclonal antibody, which binds specifically to the conserved CDR3 region of the $\mathrm{V} \alpha 24 \mathrm{~J} \alpha 18$ TCR $[13,14]$, have shown that both the percentage and absolute number of iNKT cells are lower in SLE patients than in healthy controls [15]. Another subpopulation of human $\mathrm{V} \alpha 24^{+} \mathrm{CD} 8^{+}$iNKT cells express mainly CD161 (NK1.1) and recognize CD1d molecule [16], and the cell number of this population is lower in patients with SLE than in healthy controls [17].

iNKT cell deficiency correlates with Systemic Lupus Erythematosus Disease Activity Index (SLEDAI) [15, 18], suggesting that iNKT cells are involved in the control of disease activity. Although immunosuppressive drugs correlated significantly with log-transformed absolute iNKT cell numbers $(P=0.036)$ in one study [15], the direct effect of medication on iNKT cell numbers was excluded because SLE patients without drug exposure had consistently lower iNKT cell numbers than did healthy controls. Another study found no correlation between drug therapy and the proportion of NKT cells [19]. Thus, the reduction in NKT cells in SLE patients does not appear to be a secondary response to drug therapy.

\section{Functional Deficiency in iNKT Cells in Human SLE}

In addition to the reduction in iNKT cells in human SLE, the poor response of iNKT cells to $\alpha$-GalCer has also been demonstrated in SLE patients [11], whose proliferative response of PBMCs was measured in cells cocultured with $\alpha$-GalCer. The magnitude of the responses varied between subjects, and both good and poor responders were prevalent among both patients and healthy controls. However, the proliferation indices were significantly lower in patients than in healthy controls (median 7.5 versus $28.7, P<0.001$ ) [20]. $\alpha$-GalCer potently activated iNKT cells to produce IFN- $\gamma$ and IL-4. The levels of both mRNA and cytokines in the supernatant of $\alpha$-GalCer-induced PBMCs were lower in SLE patients than in healthy controls.

The lower response of iNKT cells results mainly from their impaired function rather than a defect in the presentation ability of CD1d-bearing cells. In one study, the percentages of CD1d ${ }^{+}$PBMCs and monocytes were similar in SLE patients and healthy controls, and the expression level of CD1d on PBMCs and monocytes was also indistinguishable 
between SLE patients and healthy controls [20]. To define further the defective function of iNKT cells, sorted antigenpresenting cells (APCs) from patients or controls were cocultured with patients' iNKT cells. $\mathrm{CD}^{+} 6 \mathrm{~B} 11^{+}$iNKT cells from an SLE patient failed to proliferate upon $\alpha$-GalCer activation in the presence of monocytes from a healthy control, but iNKT cells from a healthy control were expanded successfully in the presence of monocytes from a healthy control [20]. Another study confirmed that $\mathrm{V} \alpha 24^{+} \mathrm{DN}$ iNKT cells from nonresponders fail to proliferate in the presence of APCs from responders, whereas APCs from nonresponders could expand iNKT cells from responders [11]. Another study observed an increase in apoptosis of iNKT cells from patients after 7 days of incubation with $\alpha$-GalCer [15], suggesting that the poor response of iNKT cells might partly result from the susceptibility to activation signaling-induced cell death.

Although the CD1d expression level on B cells and CD1d ${ }^{+} B$ cells is significantly lower in patients than in controls, in vitro coculture experiments indicate that monocytes, but not B cells, are effective APCs for iNKT cells [15].

These data show that iNKT cells in SLE patients are dysfunctional and suggest that activating this population may have therapeutic potential.

\section{Function of iNKT Cells Associated with SLE Disease}

Various murine models have shown the importance of iNKT cells in SLE progression and systemic disorders. These models have been analyzed and described in detail [21,22]. In this paper, we focus on recent studies that clarify the functions of iNKT cells and their associations with SLE.

4.1. Detection of Apoptotic Cells and Triggering of the Immune Response. SLE can cause severe multiple organs failure resulting from autoantibodies induction. These autoantibodies target nuclear antigens that are theoretically inaccessible. It is hypothesized that the inefficient clearance of apoptotic cells is the source of the antigen pool and that secondary necrotic bodies fuel the inflammation [23-25]. Several genetic studies have identified SLE-susceptible loci, such as CRP [26], and C1q [27], which is involved in clearance of dead cells, and these data support the concept that impaired apoptotic cell clearance is involved in SLE. Recent data suggest that cleavage of autoantigens by granzyme B during cytotoxic-T-lymphocytes- (CTL)-induced apoptosis is involved in human systemic autoimmune diseases [28]. Because CTL-induced targets are often pathogen-infected cells, the molecular mimicry between microbial antigens and autoantigens is not the only explanation for the initiation of autoimmunity after infection.

In one study of C57BL/6 mice, injection with irradiated apoptotic cells induced autoantibody production [29]. In this mouse model, deficiency in iNKT cells exacerbated the effects of the disease by increasing the production of autoantibodies and glomerular deposition of IgG immune complex [30]. Injection of apoptotic cells rapidly upregulated the expression of CD69 in splenic iNKT cells; the number of IFN- $\gamma$-producing iNKT cells decreased and the number of IL-10-producing iNKT cells increased in the injected mice. Syngenic apoptotic cell transfer into $\mathrm{CD} 19^{-/-}$mice induced iNKT cells to limit the activation of wild-type B but not $\mathrm{CD}_{1 \mathrm{~d}^{-/}} \mathrm{B}$ cells that were adoptive-transferred, respectively, into $\mathrm{CD} 19^{-/-}$recipient. The production of both IgM and IgG3 anti-DNA antibodies was reduced. These data suggest that autoreactive B cells can be regulated by iNKT cells triggered by apoptotic cells in a CD1d-dependent manner.

Increased levels of lysophosphatidylcholine and other oxidized lipids are exposed on the outer leaflet of apoptotic cells [31]. Immunization with these apoptotic cells induces the production of IgM that recognizes oxidized lipids. NKT cells may survey the lipid derivatives on apoptotic cells presented by APCs and then mediate immune tolerance. It was shown recently that apoptotic cells with phosphatidylserine exposed on the outer membrane leaflet can rapidly activate iNKT cells through recognition by T-cell Ig-like mucin-like1 (Tim-1) on iNKT cells [32]. However, airway hyperactivity was observed rather than improved outcome in this model.

4.2. Modulation of Antibody Production. The fact that SLE progression can be caused by various abnormal stimuli of lymphocyte activation suggests the presence of high immunoglobulin levels in the plasma of SLE patients. However, as expected for a heritable trait, such as SLE, analysis of the blood from relatives of SLE patients with subclinical phenotypes should more precisely reflect the pathogenic mechanism and the relationships with genetic and cellular aberrations.

High plasma IgG levels have been noted in both patients with SLE and their relatives $[12,19]$. The levels of total $\operatorname{IgG}$ and anti-dsDNA IgG in patients with SLE and their relatives are associated with a low frequency of $\mathrm{V} \alpha 24^{+}$iNKT cells. This result suggests that iNKT cells play an important role in the regulation of IgG production.

Although an inverse relationship between iNKT cells and IgG production has been observed in humans, murine models reveal a dichotomy in the regulation of IgG production by iNKT cells. One study showed that CD1d-reactive iNKT cells contribute to the development of lupus in BWF1 mice by promoting autoantibody production by B cells [7]. Another study showed that purified iNKT cells but not conventional T cells augment the in vitro secretion of IgM, IgG, and anti-dsDNA antibodies by BWF1 B cells [33] and that CD1d and CD40 are indispensable for this interaction. In addition, adoptive transfer into irradiated $n u / n u \mathrm{BALB} / \mathrm{c}$ mice of $T$ cells from the spleen of transgenic $B A L B / c$ mice expressing the TCR V $\alpha 4.4 \mathrm{~J} \alpha 24$ and $\mathrm{V} \beta 9$ chain recognizing $\mathrm{CD} 1 \mathrm{~d}$ on syngenic B cells induced lupus and severe immune complex glomerulonephritis, including the production of anti-dsDNA antibodies, in the host mice [34].

Another view suggests that iNKT cells have a suppressive role in the regulation of IgG production. In a model using heterozygous $\mathrm{J} \alpha 18^{+/-}$mice, which show similar pathophysiology to human SLE by having a reduced rather than complete absence of iNKT cells, the mice had a significantly higher anti-dsDNA IgG level and increased activation of 
autoreactive B cells [30]. Pristane-injected BALB/c mice showed increased autoantibody production and exacerbated nephritis $[35,36]$. Further studies of mice with chemically induced diseases examine that the deficiencies in CD1drestricted cells contribute to the disease.

In lipopolysaccharide-activated mouse models, reconstitution of active $\mathrm{V} \alpha 14^{+}$iNKT cells in $\mathrm{J} \alpha 18^{-/-} \mathrm{BALB} / \mathrm{c}$ mice downregulated anti-dsDNA antibody and rheumatoid factors production but did not change total IgG levels [37]. iNKT cells increased total IgG production and the appearance of activation markers on B cells through soluble mediators and helper T cells, whereas autoreactive B cells were impaired in a contact- and CD1d-dependent manner. This highlights the ability of iNKT cells to distinguish autoreactive from nonautoreactive $\mathrm{B}$ cells. Differences in CD1d expression on autoreactive and nonautoreactive B cells suggest differences in regulation between these cells because CD1d expression is higher on dsDNA-responsive autoreactive B cells.

The potent agonist of iNKT cells, $\alpha$-GalCer, is used widely to study the effect of iNKT cells in various disease models. With the administration of C8- $\alpha$-GalCer (with an 8carbon acyl chain), which skews the serum cytokine secretion toward a Th2 pattern, $50 \%$ of BWF1 mice developed lupus nephritis by 30 weeks. And 50\% of control BWF1 mice developed proteinuria by about 36 weeks [38]. In contrast to $\alpha$ GalCer, injection of $\beta$-galactosylceramide, a 12-carbon acyl chain containing glycolipid which rapidly reduced the ratio of iNKT cells in the liver and spleen [39], ameliorated lupus and reduced anti-dsDNA IgG2a production. This implies a complicated role of iNKT cells during the progression of autoimmunity and that alternative agonists of iNKT cells produce different outcomes in murine SLE models.

4.3. Modulation of the Cytokine Profile. Abnormal cytokine profiles have been implicated in the loss of immune tolerance and in a variety of autoimmune diseases. Type I NKT cells produce variety of proinflammatory cytokines, including Th1-, Th2-, and Th17-related cytokines. However, the pathophysiology of human SLE is contradictory to be related to the cytokine alteration by NKT cells in patients. Although early reports demonstrated defective Th1 and excessive Th2 responses in lupus [40], recent data suggest that the levels of both Th1 (IFN- $\gamma$, IL-12, and IL-18) and Th2 (IL-4, and IL-10) cytokines are increased in the sera of lupus patients $[41,42]$. Intracellular cytokine staining reveals comparable IL-4- and IFN- $\gamma$-expressing lymphocytes in PBMCs from SLE patients without nephritis and healthy donors $[43,44]$. However, in a subgroup of patients with severe lupus nephritis, the intracellular cytokine ratio shifts to a Th1 phenotype $[44,45]$. In disease-alleviated SLE patients, decreased IFN$\gamma$-producing cells and increased IL-4-producing $\mathrm{CD}^{+} \mathrm{T}$ cells were observed after corticoid treatment [43] and lowdose UV phototherapy [46], respectively. Although Th1/2related cytokines might contribute to SLE progression and severity, the cytokine profiles of activated iNKT cells from SLE patients are yet to be determined.

In addition to Th1- and Th2-related cytokines, iNKT cells can also express IL-17 and IL-21 [47, 48]. IL-17 has recently been implicated in the pathogenesis of SLE [49]. Evidence indicates that production of IL-17 is abnormally high in sera of SLE patients [42] and is correlated with SLE disease severity $[49,50]$. When activated by IL-17, the PBMC of patients with lupus nephritis produced higher level of total IgG, anti-dsDNA IgG, and IL-6 [51]. IL17 production is also high in murine models affected by lupus nephritis [52-55]. It shows spontaneously developed germinal centers in the spleen where IL-17 ${ }^{+} \mathrm{T}$ cells colocalize with IL-17R ${ }^{+}$B cells [55] providing the suggestion that IL$17^{+} \mathrm{T}$ cells impact $\mathrm{B}$ cells in lupus disease. The main source of IL-17 in SLE patients derives from double negative (DN) TCR $\alpha \beta^{+} \mathrm{CD} 4^{-} \mathrm{CD} 8^{-} \mathrm{T}$ cells [56]. DN T cells are scarce in healthy individuals, but they expand in peripheral blood of SLE patients and infiltrate into kidney with lupus nephritis where they produce proinflammatory cytokines, including IL-17, IL- $1 \beta$, and IFN- $\gamma$ [56-58]. Also in lupus murine models, DN T cells are important IL-17 producer [52]. It also demonstrates elevated plasma levels of IL-21 as well as percentages of IL-21 expressing $\mathrm{T}$ cells in SLE patients compared with healthy controls $[59,60]$; nevertheless, there is no correlation between IL-21 and disease severity or antids DNA titers [59].

The study of CD1-lipid reactive $\mathrm{T}$ cells is much more complicated in humans than in mice. In addition to CD1d, CD1a-, b-, and c-restricted $\mathrm{T}$ cells in humans are relatively diverse with $\mathrm{CD}^{+}, \mathrm{CD}^{+}$, or $\mathrm{CD} 4^{-} \mathrm{CD}^{-}$double negative (DN) populations. Although V $\alpha 24$ DN NKT cells are numerically decreased in SLE patients, the influence of the subsets of other CD1-lipid reactive $\mathrm{T}$ cells on SLE pathogenesis in humans should be further investigated.

In murine models, treatment of adult BWF1 mice (age 8-12 weeks) with $\alpha$-GalCer exacerbated the disease activity, whereas treatment of young BWF1 mice (age 4 weeks) ameliorated SLE symptoms [61]. Moreover, transfer of NK1.1 ${ }^{+}$T cells from aged SLE mice to young BWF1 mice (before the onset of renal failure) induced proteinuria and swelling of the glomeruli. It has been indicated that iNKT cells expand in aged BWF1 mice and the authors reported that $\alpha$-GalCer administration induced predominant IFN- $\gamma$ production in old mice [7]. Use of a blocking anti-CD1d monoclonal antibody to treat BWF1 mice augmented the Th2 responses and ameliorated lupus [61]. These results suggest that the impact of $\alpha$-GalCer treatment on disease in BWF1 mice varies with age and imply that the cytokine profile of iNKT cells influences the progression of SLE.

In pristane-induced nephritis models, the effect of $\alpha$ GalCer differs between mouse strains. In BALB/c mice, Th2 responses are induced by treatment with $\alpha$-GalCer, which protects mice against nephritis. Conversely, in SJL/J mice, treatment with $\alpha$-GalCer increases the Th1 responses and exacerbates disease [62]. The differences in the effect of $\alpha$ GalCer seem to correlate with the cytokine profile produced by activated iNKT cells. It is the common regulatory mechanism in several autoimmune diseases, such as experimental autoimmune encephalomyelitis, and type 1 diabetes.

iNKT cells mediate various immune responses, including maintenance of self-tolerance, tumor surveillance, and the response to microbial pathogens. Given the limited TCR 


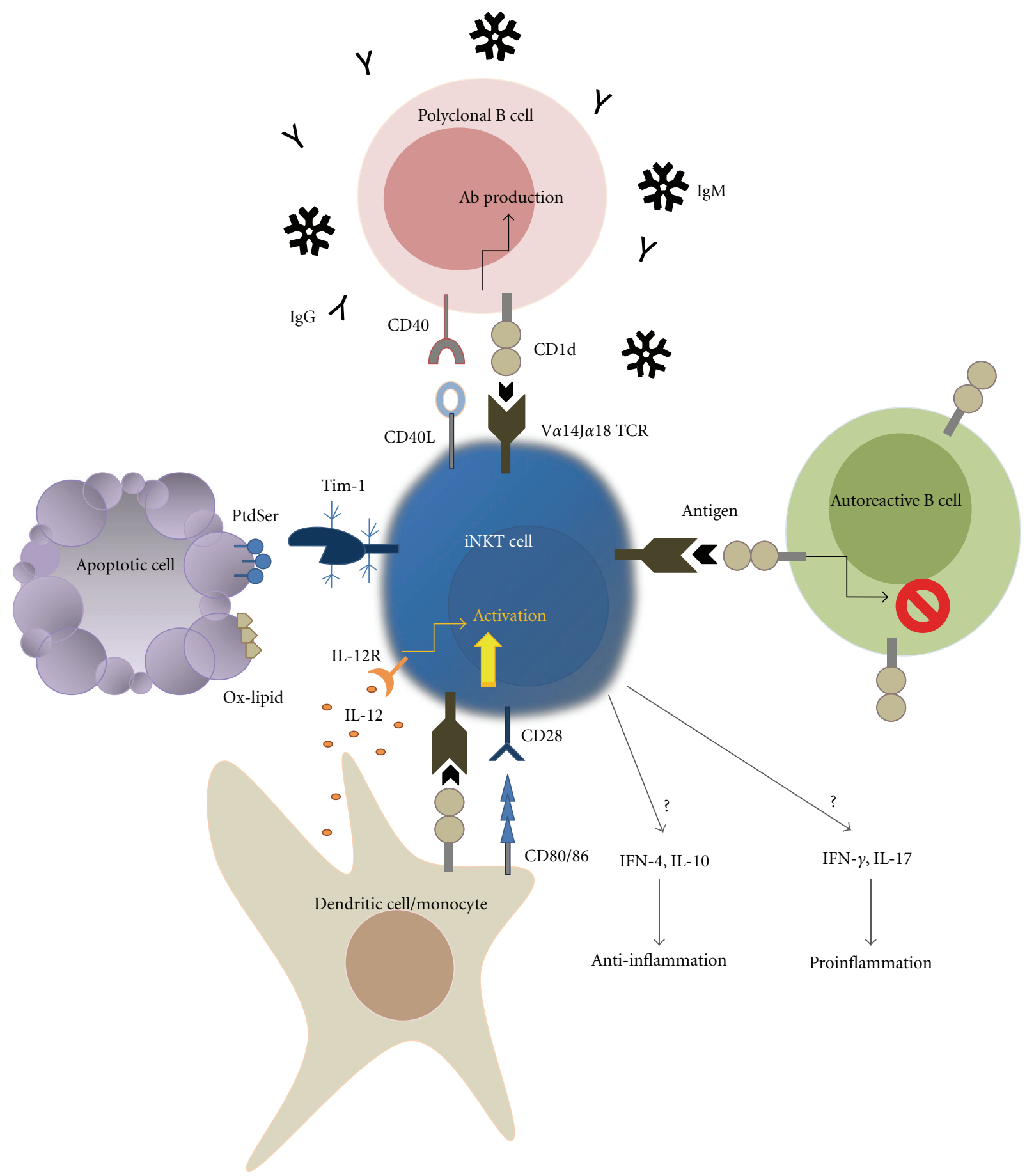

FIGURE 1: The function of iNKT cells in murine lupus models. iNKT cells in the mouse that express invariant TCR, V $\alpha 14 \mathrm{~J} \alpha 18$, are CD1drestricted T lymphocytes. The antigens presented by CD1d can be microbial components, endogenous antigen, iGb3, or oxidized lipid (Oxlipid) derivatives from apoptotic cells. DCs and monocytes are potent APCs that activate iNKT cells both directly through TCR engagement and indirectly through IL-12. Immediately upon activation, iNKT cells release Th1-, Th2-, and T17-related cytokines, depending on the antigen presented and/or the characteristics of the APCs. The proinflammatory cytokines, IFN- $\gamma$ and IL-17, lead predominantly to SLE exacerbation. iNKT cells can sense apoptotic blebs through Tim-1, which recognizes phosphatidylserine (PtdSer) exposed on the outer leaflet membrane, and can mediate immune suppression (see text). By contrast, iNKT cells activate B cells and thus upregulate total IgG and IgM levels in a CD1d-dependent manner, but iNKT cells can also inhibit the activation of autoreactive B cells. CD1d expression levels suggest that iNKT cells are capable of discriminating self- from nonself-reactive B cells. 
diversity, attention has focused on the mechanisms underlying the activation of iNKT cells [63]. In addition to the microbial glycolipid antigens engaging directly with the invariant TCR on iNKT cells [3], indirect activation of iNKT cells by cytokines or endogenous antigen presentation through microbial-stimulated dendritic cells (DCs) is also possible [64-66]. This may explain the ability of various stimuli to activate iNKT cells in the body and implies that iNKT cells might mediate both beneficial and detrimental outcomes depending on the milieu produced by the activated DCs.

The beneficial roles of iNKT cells are involved in immune tolerance and can ameliorate or prevent tissue inflammation $[67,68]$. The suppressive effect is mediated globally through tolerogenic DCs, B cells, or regulatory $\mathrm{T}$ cells or directly by skewed cytokine production and induction of apoptosis through Fas-FasL engagement of autoreactive lymphocytes [69]. SLE patients have reduced proportions and functions of iNKT cells, which imply that the suppressive effect is mediated by this population. However, a reduced population of iNKT cells cannot be a diagnostic clinical marker of SLE because the frequency of iNKT cells varies markedly between healthy people. Although the suppressive effect was identified recently in a murine lupus model, the function of iNKT cells in humans needs to be clarified.

Long-term anergy of iNKT cells by reactivation can be induced in mice [70]. The unresponsiveness to $\alpha \mathrm{GalCer}$ includes reduced proliferative activity and failure of IFN- $\gamma$ production. This suggests that the aberrant proportion and function of iNKT cells in SLE patients may reflect only the outcome after repeated exposure to cognate self-antigens. By contrast, Green et al. did not exclude the possibility that the reduced level of iNKT cells results from attack by upregulated antibody in SLE patients [12]. Therefore, iNKT cells may be a potential therapeutic target in the treatment of SLE patients, although the complicated interactions between iNKT cells and other immune cells and the exact function of iNKT cells require further consideration.

\section{Conclusion}

In this paper, we have discussed the association between iNKT cells and SLE in clinical and murine models. In human SLE patients, the reduced proportion and function of iNKT cells correlate with disease activity and iNKT cells correlate inversely with IgG levels. Recent studies indicate that iNKT cells can sense apoptotic cells and mediate immune tolerance and suggest that iNKT cells can distinguish autoreactive B cells from nonautoreactive $B$ cells to suppress autoreactive antibody production in a CD1d-dependent manner. However, other studies have reported that iNKT cells upregulate total IgG and IgM levels (Figure 1). These findings suggest that iNKT cells are involved in suppressive regulation in SLE.

\section{Acknowledgments}

This work was supported by the National Science Council, Taiwan. (NSC100-3112-B-016-001, NSC99-2320-B-016-001-
MY3), Tri-service General Hospital foundation (TSGHC101-009-0S01), National Health Research Institutes (NHRI100A1-PDCO-0809111), Ministry of Economic Affairs (100EC-17-A-20-S1-028), and in part by the C. Y. Foundation for Advancement of Education, Sciences and Medicine.

\section{References}

[1] B. L. Kotzin, "Systemic lupus erythematosus," Cell, vol. 85, no. 3, pp. 303-306, 1996.

[2] D. I. Godfrey, S. Stankovic, and A. G. Baxter, "Raising the NKT cell family," Nature Immunology, vol. 11, no. 3, pp. 197-206, 2010.

[3] A. Bendelac, P. B. Savage, and L. Teyton, "The biology of NKT cells," Annual Review of Immunology, vol. 25, pp. 297-336, 2007.

[4] L. Wu, C. L. Gabriel, V. V. Parekh, and L. Van Kaer, "Invariant natural killer T cells: innate-like $\mathrm{T}$ cells with potent immunomodulatory activities," Tissue Antigens, vol. 73, no. 6, pp. 535$545,2009$.

[5] S. Miyake and T. Yamamura, "NKT cells and autoimmune diseases: unraveling the complexity," Current Topics in Microbiology and Immunology, vol. 314, pp. 251-267, 2007.

[6] J. Q. Yang, T. Chun, H. Liu et al., "CD1d deficiency exacerbates inflammatory dermatitis in MRL-lpr/lpr mice," European Journal of Immunology, vol. 34, no. 6, pp. 1723-1732, 2004.

[7] C. Forestier, A. Molano, J. S. Im et al., "Expansion and hyperactivity of CD1d-restricted NKT cells during the progression of systemic lupus erythematosus in (New Zealand Black $\times$ New Zealand White)F1 mice," Journal of Immunology, vol. 175, no. 2, pp. 763-770, 2005.

[8] J. Q. Yang, V. Saxena, H. Xu, L. Van Kaer, C. R. Wang, and R. R. Singh, "Repeated $\alpha$-galactosylceramide administration results in expansion of NKT cells and alleviates inflammatory dermatitis in MRL-lpr/lpr mice," Journal of Immunology, vol. 171, no. 8, pp. 4439-4446, 2003.

[9] T. Sumida, A. Sakamoto, H. Murata et al., "Selective reduction of $\mathrm{T}$ cells bearing invariant $\mathrm{V} \alpha 24 \mathrm{~J} \alpha \mathrm{Q}$ antigen receptor in patients with systemic sclerosis," Journal of Experimental Medicine, vol. 182, no. 4, pp. 1163-1168, 1995.

[10] T. Sumida, T. Maeda, M. Taniguchi, K. Nishioka, and W. Stohl, "TCR AV24 gene expression in double negative T cells in systemic lupus erythematosus," Lupus, vol. 7, no. 8, pp. 565568, 1998.

[11] S. Kojo, Y. Adachi, H. Keino, M. Taniguchi, and T. Sumida, "Dysfunction of T cell receptor AV24AJ18+, BV11' doublenegative regulatory natural killer $\mathrm{T}$ cells in autoimmune diseases," Arthritis and Rheumatism, vol. 44, no. 5, pp. 1127-1138, 2001.

[12] M. R. J. Green, A. S. M. Kennell, M. J. Larche, M. H. Seifert, D. A. Isenberg, and M. R. Salaman, "Natural killer T cells in families of patients with systemic lupus erythematosus: their possible role in regulation of IGG production," Arthritis and Rheumatism, vol. 56, no. 1, pp. 303-310, 2007.

[13] J. E. Boyson, B. Rybalov, L. A. Koopman et al., "CD1d and invariant NKT cells at the human maternal-fetal interface," Proceedings of the National Academy of Sciences of the United States of America, vol. 99, no. 21, pp. 13741-13746, 2002.

[14] S. Y. Thomas, R. Hou, J. E. Boyson et al., "CD1D-restricted NKT cells express a chemokine receptor profile indicative of $\mathrm{Th}_{1}$-type inflammatory homing cells," Journal of Immunology, vol. 171, no. 5, pp. 2571-2580, 2003. 
[15] Y. N. Cho, S. J. Kee, S. J. Lee, S. R. Seo, T. J. Kim, S. S. Lee et al., "Numerical and functional deficiencies of natural killer T cells in systemic lupus erythematosus: their deficiency related to disease activity," Rheumatology, vol. 50, pp. 1054-1063, 2011.

[16] T. Takahashi, S. Chiba, M. Nieda et al., "Cutting edge: analysis of human $\mathrm{V} \alpha 24^{+} \mathrm{CD} 8^{+} \mathrm{NKT}$ cells activated by $\alpha$ galactosylceramide-pulsed monocyte-derived dendritic cells," Journal of Immunology, vol. 168, no. 7, pp. 3140-3144, 2002.

[17] A. Mitsuo, S. Morimoto, Y. Nakiri et al., "Decreased $\mathrm{CD} 161^{+} \mathrm{CD}^{+} \mathrm{T}$ cells in the peripheral blood of patients suffering from rheumatic diseases," Rheumatology, vol. 45, no. 12, pp. 1477-1484, 2006.

[18] Y. Oishi, T. Sumida, A. Sakamoto et al., "Selective reduction and recovery of invariant $\mathrm{V} \alpha 24 \mathrm{~J} \alpha \mathrm{Q} \mathrm{T}$ cell receptor $\mathrm{T}$ cells in correlation with disease activity in patients with systemic lupus erythematosus," Journal of Rheumatology, vol. 28, no. 2, pp. 275-283, 2001.

[19] J. Wither, Y. C. Cai, S. Lim et al., "Reduced proportions of natural killer $\mathrm{T}$ cells are present in the relatives of lupus patients and are associated with autoimmunity," Arthritis Research and Therapy, vol. 10, no. 5, article R108, 2008.

[20] Y. N. Cho, S. J. Kee, S. J. Lee, S. R. Seo, T. J. Kim, S. S. Lee et al., "Numerical and functional deficiencies of natural killer T cells in systemic lupus erythematosus: their deficiency related to disease activity," Rheumatology, vol. 50, no. 6, pp. 1054-1063, 2011.

[21] L. Gabriel, B. J. Morley, and N. J. Rogers, "The role of iNKT cells in the immunopathology of systemic lupus erythematosus," Annals of the New York Academy of Sciences, vol. 1173, pp. 435-441, 2009.

[22] M. Godó, T. Sessler, and P. Hamar, "Role of invariant natural killer T (iNKT) cells in systemic lupus erythematosus," Current Medicinal Chemistry, vol. 15, no. 18, pp. 1778-1787, 2008.

[23] L. A. Casciola-Rosen, G. Anhalt, and A. Rosen, "Autoantigens targeted in systemic lupus erythematosus are clustered in two populations of surface structures on apoptotic keratinocytes," Journal of Experimental Medicine, vol. 179, no. 4, pp. 13171330, 1994.

[24] U. S. Gaipl, A. Kuhn, A. Sheriff et al., "Clearance of apoptotic cells in human SLE," Current Directions in Autoimmunity, vol. 9, pp. 173-187, 2006.

[25] L. E. Muñoz, C. Janko, G. E. Grossmayer et al., "Remnants of secondarily necrotic cells fuel inflammation in systemic lupus erythematosus," Arthritis and Rheumatism, vol. 60, no. 6, pp. 1733-1742, 2009.

[26] B. Rhodes, B. G. Fürnrohr, and T. J. Vyse, "C-reactive protein in rheumatology: biology and genetics," Nature Reviews Rheumatology, vol. 7, no. 5, pp. 282-289, 2011.

[27] J. S. Navratil, C. C. Liu, and J. M. Ahearn, "Apoptosis and autoimmunity," Immunologic Research, vol. 36, no. 1-3, pp. 312, 2006.

[28] E. Darrah and A. Rosen, "Granzyme B cleavage of autoantigens in autoimmunity," Cell Death and Differentiation, vol. 17, no. 4, pp. 624-632, 2010.

[29] D. Mevorach, J. L. Zhou, X. Song, and K. B. Elkon, "Systemic exposure to irradiated apoptotic cells induces autoantibody production," Journal of Experimental Medicine, vol. 188, no. 2, pp. 387-392, 1998.

[30] F. Wermeling, S. M. Lind, E. D. Jordö, S. L. Cardell, and M. C. I. Karlsson, "Invariant NKT cells limit activation of autoreactive CD1d-positive B cells," Journal of Experimental Medicine, vol. 207, no. 5, pp. 943-952, 2010.
[31] M. K. Chang, C. J. Binder, Y. I. Miller et al., "Apoptotic cells with oxidation-specific epitopes are immunogenic and proinflammatory," Journal of Experimental Medicine, vol. 200, no. 11, pp. 1359-1370, 2004.

[32] H. H. Lee, E. H. Meyer, S. Goya et al., "Apoptotic cells activate NKT cells through T cell Ig-like mucin-like-1 resulting in airway hyperreactivity," Journal of Immunology, vol. 185, no. 9, pp. 5225-5235, 2010.

[33] T. Takahashi and S. Strober, "Natural killer T cells and innate immune B cells from lupus-prone NZB/W mice interact to generate IgM and IgG autoantibodies," European Journal of Immunology, vol. 38, no. 1, pp. 156-165, 2008.

[34] D. Zeng, M. Dick, L. Cheng et al., "Subsets of transgenic T cells that recognize CD1 induce or prevent murine lupus: role of cytokines," Journal of Experimental Medicine, vol. 187, no. 4, pp. 525-536, 1998.

[35] J. Q. Yang, X. Wen, H. Liu et al., "Examining the role of CD1d and natural killer $\mathrm{T}$ cells in the development of nephritis in a genetically susceptible lupus model," Arthritis and Rheumatism, vol. 56, no. 4, pp. 1219-1233, 2007.

[36] J. Q. Yang, A. K. Singh, M. T. Wilson et al., "Immunoregulatory role of CD1d in the hydrocarbon oil-induced model of lupus nephritis," Journal of Immunology, vol. 171, no. 4, pp. 2142-2153, 2003.

[37] J. Q. Yang, X. Wen, P. J. Kim, and R. R. Singh, "Invariant NKT cells inhibit autoreactive B cells in a contact- and CD1ddependent manner," Journal of Immunology, vol. 186, no. 3, pp. 1512-1520, 2011.

[38] S. R. Morshed, T. Takahashi, P. B. Savage, N. Kambham, and S. Strober, " $\beta$-galactosylceramide alters invariant natural killer T cell function and is effective treatment for lupus," Clinical Immunology, vol. 132, no. 3, pp. 321-333, 2009.

[39] J. R. Ortaldo, H. A. Young, R. T. Winkler-Pickett Jr., E. W. Bere, W. J. Murphy, and R. H. Wiltrout, "Dissociation of NKT stimulation, cytokine induction, and NK activation in vivo by the use of distinct TCR-binding ceramides," Journal of Immunology, vol. 172, no. 2, pp. 943-953, 2004.

[40] F. A. Houssiau, C. Lefebvre, M. Vanden Berghe, M. Lambert, J. P. Devogelaer, and J. C. Renauld, "Serum interleukin 10 titers in systemic lupus erythematosus reflect disease activity," Lupus, vol. 4, no. 5, pp. 393-395, 1995.

[41] A. Gigante, M. L. Gasperini, A. Afeltra et al., "Cytokines expression in SLE nephritis," European Review for Medical and Pharmacological Sciences, vol. 15, no. 1, pp. 15-24, 2011.

[42] C. K. Wong, C. Y. Ho, E. K. Li, and C. W. K. Lam, "Elevation of proinflammatory cytokine (IL-18, IL-17, IL-12) and $\mathrm{Th}_{2}$ cytokine (IL-4) concentrations in patients with systemic lupus erythematosus," Lupus, vol. 9, no. 8, pp. 589-593, 2000.

[43] G. Nagy, E. Pallinger, P. Antal-Szalmas et al., "Measurement of intracellular interferon-gamma and interleukin-4 in whole blood $\mathrm{T}$ lymphocytes from patients with systemic lupus erythematosus," Immunology Letters, vol. 74, no. 3, pp. 207210, 2000.

[44] M. Akahoshi, H. Nakashima, Y. Tanaka et al., " $\mathrm{Th}_{1} / \mathrm{Th}_{2}$ balance of peripheral T helper cells in systemic lupus erythematosus," Arthritis and Rheumatism, vol. 42, no. 8, pp. 1644-1648, 1999.

[45] K. Masutani, M. Akahoshi, K. Tsuruya et al., "Predominance of $\mathrm{Th}_{1}$ immune response in diffuse proliferative lupus nephritis," Arthritis and Rheumatism, vol. 44, no. 9, pp. 2097-2106, 2001.

[46] A. Szegedi, E. Simics, M. Aleksza et al., "Ultraviolet-A1 phototherapy modulates $\mathrm{Th}_{1} / \mathrm{Th}_{2}$ and $\mathrm{Tc}_{1} / \mathrm{Tc}_{2}$ balance in patients with systemic lupus erythematosus," Rheumatology, vol. 44, no. 7, pp. 925-931, 2005. 
[47] J. M. Coquet, K. Kyparissoudis, D. G. Pellicci et al., "IL-21 is produced by NKT cells and modulates NKT cell activation and cytokine production," Journal of Immunology, vol. 178, no. 5, pp. 2827-2834, 2007.

[48] M. L. Michel, D. Mendes-da-Cruz, A. C. Keller et al., "Critical role of ROR- $\gamma \mathrm{t}$ in a new thymic pathway leading to IL17-producing invariant NKT cell differentiation," Proceedings of the National Academy of Sciences of the United States of America, vol. 105, no. 50, pp. 19845-19850, 2008.

[49] C. K. Wong, L. C. W. Lit, L. S. Tam, E. K. M. Li, P. T. Y. Wong, and C. W. K. Lam, "Hyperproduction of IL-23 and IL17 in patients with systemic lupus erythematosus: implications for $\mathrm{Th}_{17}$-mediated inflammation in auto-immunity," Clinical Immunology, vol. 127, no. 3, pp. 385-393, 2008.

[50] A. Doreau, A. Belot, J. Bastid et al., "Interleukin 17 acts in synergy with B cell-activating factor to influence B cell biology and the pathophysiology of systemic lupus erythematosus," Nature Immunology, vol. 10, no. 7, pp. 778-785, 2009.

[51] G. Dong, R. Ye, W. Shi et al., "IL-17 induces autoantibody overproduction and peripheral blood mononuclear cell overexpression of IL-6 in lupus nephritis patients," Chinese Medical Journal, vol. 116, no. 4, pp. 543-548, 2003.

[52] Z. Zhang, V. C. Kyttaris, and G. C. Tsokos, "The role of IL23/IL-17 axis in lupus nephritis," Journal of Immunology, vol. 183, no. 5, pp. 3160-3169, 2009.

[53] H. K. Kang, M. Liu, and S. K. Datta, "Low-dose peptide tolerance therapy of lupus generates plasmacytoid dendritic cells that cause expansion of autoantigen-specific regulatory T cells and contraction of inflammatory $\mathrm{Th}_{17}$ cells," Journal of Immunology, vol. 178, no. 12, pp. 7849-7858, 2007.

[54] H. C. Hsu, T. Zhou, H. Kim et al., "Production of a novel class of polyreactive pathogenic autoantibodies in BXD2 mice causes glomerulonephritis and arthritis," Arthritis and Rheumatism, vol. 54, no. 1, pp. 343-355, 2006.

[55] H. C. Hsu, P. A. Yang, J. Wang et al., "Interleukin 17-producing $\mathrm{T}$ helper cells and interleukin 17 orchestrate autoreactive germinal center development in autoimmune BXD2 mice," Nature Immunology, vol. 9, no. 2, pp. 166-175, 2008.

[56] J. C. Crispín, M. Oukka, G. Bayliss et al., "Expanded double negative T cells in patients with systemic lupus erythematosus produce IL-17 and infiltrate the kidneys," Journal of Immunology, vol. 181, no. 12, pp. 8761-8766, 2008.

[57] J. C. Crispín and G. C. Tsokos, "Human TCR- $\alpha \beta^{+}$CD4- CD8 ${ }^{-}$ $\mathrm{T}$ cells can derive from $\mathrm{CD} 8^{+} \mathrm{T}$ cells and display an inflammatory effector phenotype," Journal of Immunology, vol. 183, no. 7, pp. 4675-4681, 2009.

[58] Y. Wang, S. Ito, Y. Chino et al., "Laser microdissection-based analysis of cytokine balance in the kidneys of patients with lupus nephritis," Clinical and Experimental Immunology, vol. 159, no. 1, pp. 1-10, 2010.

[59] S. Dolff, W. H. Abdulahad, J. Westra et al., "Increase in IL-21 producing T-cells in patients with systemic lupus erythematosus," Arthritis Research and Therapy, vol. 13, no. 5, article R157, 2011.

[60] C. K. Wong, P. T. Y. Wong, L. S. Tam, E. K. Li, D. P. Chen, and C. W. K. Lam, "Elevated production of B Cell Chemokine CXCL13 is correlated with systemic lupus erythematosus disease activity," Journal of Clinical Immunology, vol. 30, no. 1, pp. 45-52, 2010.

[61] D. Zeng, Y. Liu, S. Sidobre, M. Kronenberg, and S. Strober, "Activation of natural killer T cells in NZB/W mice induces $\mathrm{Th}_{1}$-type immune responses exacerbating lupus," Journal of Clinical Investigation, vol. 112, no. 8, pp. 1211-1222, 2003.
[62] A. K. Singh, J. Q. Yang, V. V. Parekh et al., "The natural killer $\mathrm{T}$ cell ligand $\alpha$-galactosylceramide prevents or promotes pristane-induced lupus in mice," European Journal of Immunology, vol. 35, no. 4, pp. 1143-1154, 2005.

[63] E. Tupin, Y. Kinjo, and M. Kronenberg, "The unique role of natural killer T cells in the response to microorganisms," Nature Reviews Microbiology, vol. 5, no. 6, pp. 405-417, 2007.

[64] M. Brigl, L. Bry, S. C. Kent, J. E. Gumperz, and M. B. Brenner, "Mechanism of CD1d-restricted natural killer T cell activation during microbial infection," Nature Immunology, vol. 4, no. 12, pp. 1230-1237, 2003.

[65] J. Mattner, K. L. DeBord, N. Ismail et al., "Exogenous and endogenous glycolipid antigens activate NKT cells during microbial infections," Nature, vol. 434, no. 7032, pp. 525-529, 2005.

[66] T. Mallevaey, J. P. Zanetta, C. Faveeuw et al., "Activation of invariant NKT cells by the helminth parasite schistosoma mansoni," Journal of Immunology, vol. 176, no. 4, pp. 24762485, 2006.

[67] E. Tupin, M. R. E. I. Benhnia, Y. Kinjo et al., "NKT cells prevent chronic joint inflammation after infection with Borrelia burgdorferi," Proceedings of the National Academy of Sciences of the United States of America, vol. 105, no. 50, pp. 19863-19868, 2008.

[68] Y. Liu, A. Teige, E. Mondoc, S. Ibrahim, R. Holmdahl, and S. Issazadeh-Navikas, "Endogenous collagen peptide activation of CD1d-restricted NKT cells ameliorates tissue-specific inflammation in mice," Journal of Clinical Investigation, vol. 121, no. 1, pp. 249-264, 2011.

[69] M. Nowak and J. Stein-Streilein, "Invariant NKT cells and tolerance," International Reviews of Immunology, vol. 26, no. 1-2, pp. 95-119, 2007.

[70] V. V. Parekh, M. T. Wilson, D. Olivares-Villagómez et al., “Glycolipid antigen induces long-term natural killer $\mathrm{T}$ cell anergy in mice," Journal of Clinical Investigation, vol. 115, no. 9, pp. 2572-2583, 2005. 


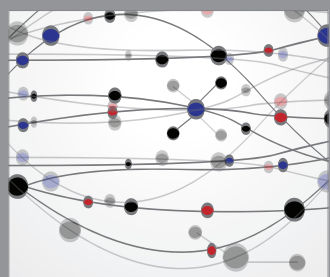

The Scientific World Journal
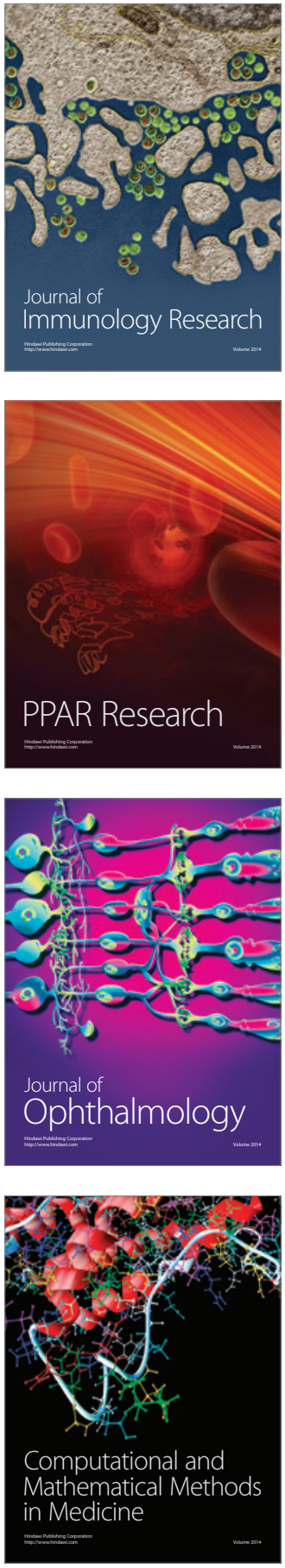

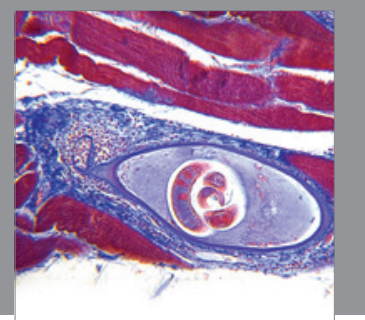

Gastroenterology

Research and Practice
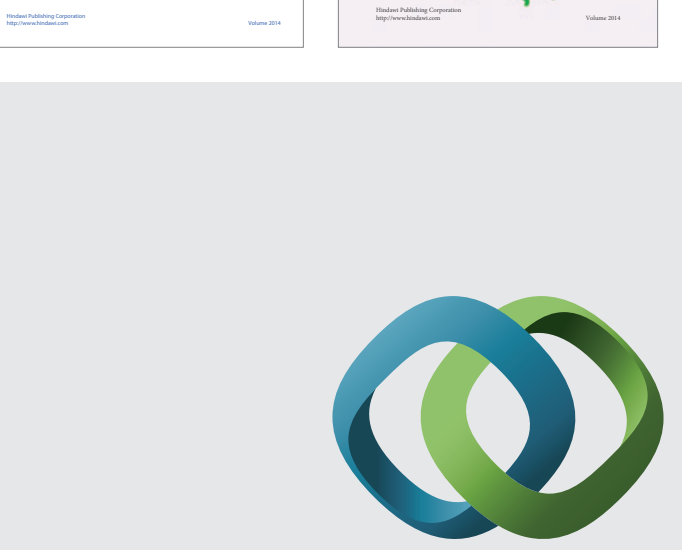

\section{Hindawi}

Submit your manuscripts at

http://www.hindawi.com
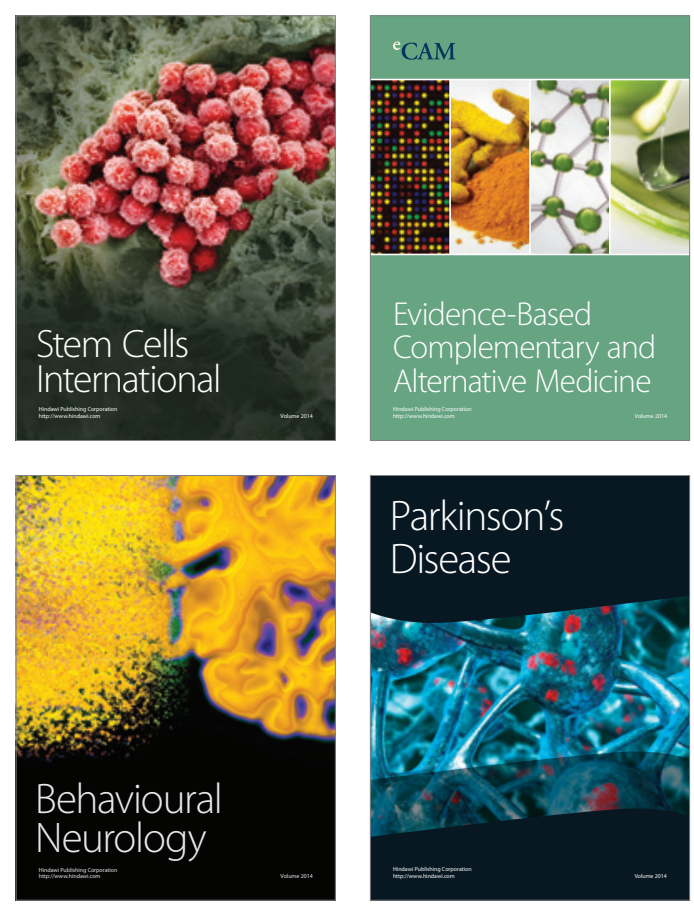

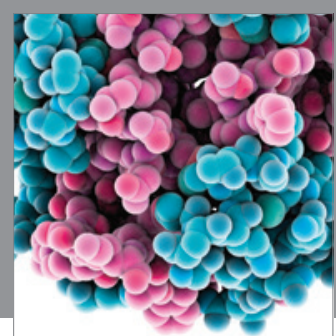

Journal of
Diabetes Research

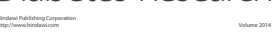

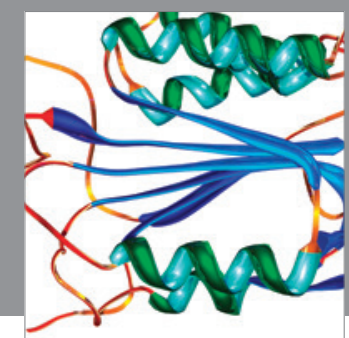

Disease Markers
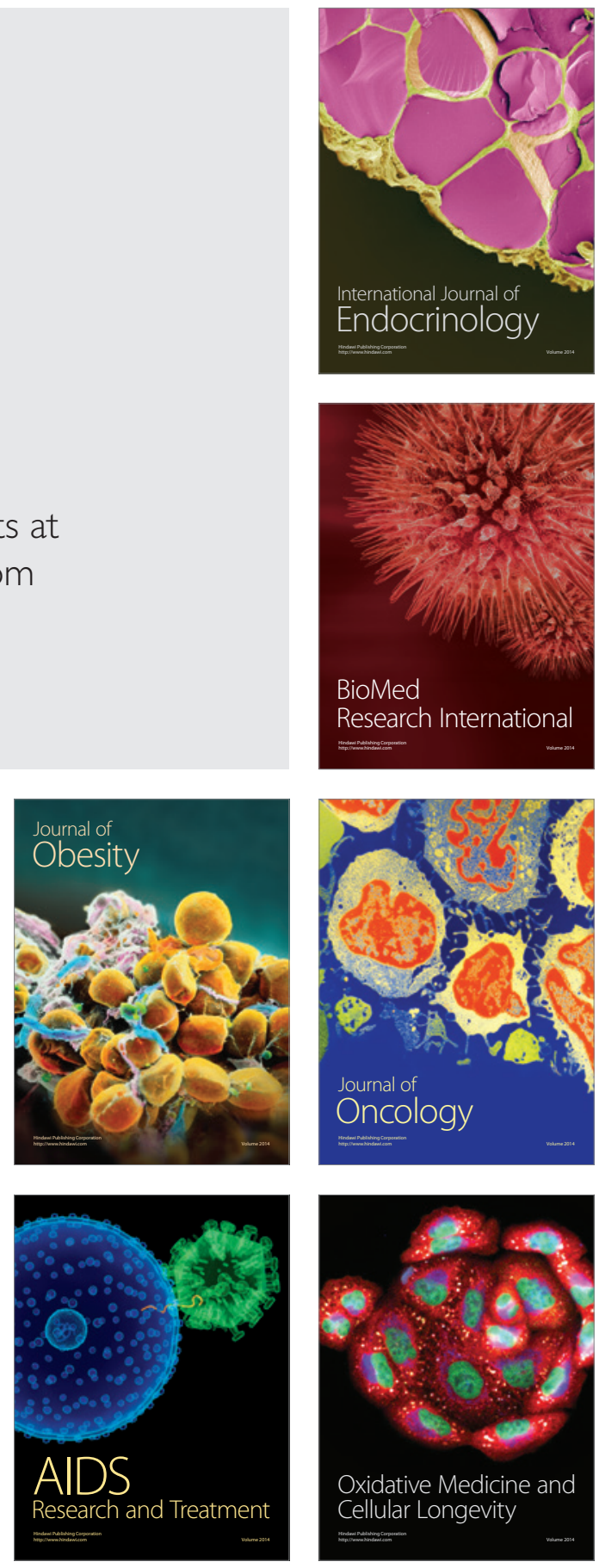